\title{
BMJ Open A pharmacoeconomic approach to assessing the costs and benefits of air quality interventions that improve health: a case study
}

James Lomas, ${ }^{1}$ Laetitia Schmitt, ${ }^{2}$ Sally Jones, ${ }^{3}$ Maureen McGeorge, ${ }^{4}$ Elizabeth Bates, ${ }^{3,5}$ Mike Holland, ${ }^{6}$ Duncan Cooper, ${ }^{7}$ Richard Crowther, ${ }^{8}$ Mike Ashmore, ${ }^{1}$ David Rojas-Rueda, ${ }^{9}$ Helen Weatherly, ${ }^{1}$ Gerry Richardson, ${ }^{1}$ Laura Bojke ${ }^{1}$

To cite: Lomas J, Schmitt L, Jones S, et al. A pharmacoeconomic approach to assessing the costs and benefits of air quality interventions that improve health: a case study. BMJ Open 2016;6:e010686. doi:10.1136/bmjopen-2015010686

- Prepublication history and additional material is available. To view please visit the journal (http://dx.doi.org/ 10.1136/bmjopen-2015010686).

Received 26 November 2015 Revised 3 March 2016 Accepted 7 April 2016

CrossMark

For numbered affiliations see end of article.

Correspondence to Dr James Lomas; james.lomas@york.ac.uk

\section{ABSTRACT}

Objective: This paper explores the use of pharmacoeconomic methods of valuation to health impacts resulting from exposure to poor air quality. In using such methods, interventions that reduce exposure to poor air quality can be directly compared, in terms of value for money (or cost-effectiveness), with competing demands for finite resources, including other public health interventions.

Design: Using results estimated as part of a health impact assessment regarding a West Yorkshire Low Emission Zone strategy, this paper quantifies costsaving and health-improving implications of transport policy through its impact on air quality.

Data source: Estimates of health-related quality of life and the National Health Service (NHS)/Personal Social Services (PSS) costs for identified health events were based on data from Leeds and Bradford using peerreviewed publications or Office for National Statistics releases.

Population: Inhabitants of the area within the outer ring roads of Leeds and Bradford.

Main outcomes measures: NHS and PSS costs and quality-adjusted life years (QALYs).

Results: Averting an all-cause mortality death generates 8.4 QALYs. Each coronary event avoided saves $£ 28000$ in NHS/PSS costs and generates 1.1 QALYs. For every fewer case of childhood asthma, there will be NHS/PSS cost saving of $£ 3000$ and a health benefit of 0.9 QALYs. A single term, low birthweight birth avoided saves $£ 2000$ in NHS/PSS costs. Preventing a preterm birth saves $£ 24000$ in NHS/PSS costs and generates 1.3 QALYs. A scenario modelled in the West Yorkshire Low Emission Zone Feasibility Study, where pre-EURO 4 buses and HGVs are upgraded to EURO 6 by 2016 generates an annual benefit of $£ 2.08$ million and a one-off benefit of $£ 3.3$ million compared with a net present value cost of implementation of $£ 6.3$ million.

Conclusions: Interventions to improve air quality and health should be evaluated and where improvement of population health is the primary objective, cost-effectiveness analysis using a

\section{Strengths and limitations of this study}

- Applying cost and quality-adjusted life year (QALY) methods from economic evaluation in healthcare allows the assessment of costeffectiveness from a healthcare perspective and facilitates comparison with other health interventions.

- The methods outlined above will allow local authorities to prioritise low emission strategies (supported by health and economic benefits) alongside other public health interventions.

- A fuller consideration of uncertainty would take in to account the following stochastic elements: estimated reduction in emissions, modelled dispersion, health effects of exposure to air pollutants, values of health impacts and assumptions made in generating estimates of QALY.

- The analysis also only assesses one intervention (the introduction of pre-EURO 4 buses and HGVs are upgraded to EURO 6 by 2016). However, decision-makers are likely to be faced with a multitude of competing alternatives, both air quality interventions and other public health interventions.

NHS/PSS costs and QALYs framework is an appropriate methodology.

\section{INTRODUCTION}

In total, 40000 deaths are attributable to exposure to outdoor air pollution, each year in the UK. ${ }^{1}$ As a result, there is an increasing interest in studying the relationship between air quality and health, and the availability of evidence to support this association is accumulating; ${ }^{2-4}$ with air pollution having been described as 'the public health problem that won't go away'. Interventions aimed at 
improving air quality incur costs and generate benefits. Establishing the value for money of these interventions is a crucial criterion for policymakers' decision-making. In particular, it is important that value for money is established in a manner that is consistent with other types of intervention to facilitate comparison, for example, between a strategy that improves air quality and the introduction of a smoking cessation campaign. This can ensure that the most cost-effective policies are implemented to maximise population health given fixed, or even shrinking, budgets.

To determine cost-effectiveness, we can look to the methods used by the National Institute for Heath and Care Excellence (NICE), which is responsible for making recommendations for health-improving interventions in the UK. NICE has substantial experience in employing cost-effectiveness evidence to determine appropriate guidance on the use of pharmacological treatments, for example, in its decision to not recommend $\beta$-interferon and glatiramer acetate for the treatment of multiple sclerosis in 2002. ${ }^{6}$ Recently, NICE's remit has extended to include guidance on public health interventions for which evidence is also centred on the estimated cost-effectiveness, for example, guidance on interventions to promote smoking cessation. ${ }^{7}$ While NICE develops guidance specifically for England and Wales, its evidence is often seen internationally and there are similar organisations that exist in other countries, for example, PBAC (Australia), CADTH (Canada) and HITAP (Thailand) to name but three. The process employed by NICE is rigorous and accountable, and by employing a generic measure of health, quality-adjusted life years (QALYs, note that another generic measure of health, disability-adjusted life years (DALYs), has been proposed for use with air quality, ${ }^{89}$ but are not discussed here given that it is not used by NICE), it ensures that estimates of cost-effectiveness from different types of health-promoting interventions are comparable and decision-making consistent. For this reason, this paper explores the use of a QALY approach to health valuation and cost-effectiveness analysis to compare interventions that reduce exposure to poor air quality.

This research is timely for two reasons. First, NICE is working towards a set of guidance regarding outdoor air quality and health anticipated to be published in June 2017. And second, air pollution (and in particular roadtraffic pollution) is a major concern in cities throughout Europe and in particular, the UK. The European Commission and the Supreme Court has issued a challenge to the Department for Environment, Food and Rural Affairs (DEFRA) to ensure full compliance with nitrogen dioxide $\left(\mathrm{NO}_{2}\right)$ limit values by 2025 . In order to achieve this, plans for the introduction of 'clean air zones' (CAZs) have been developed throughout the UK. The CAZ strategies implemented will have similar types of health outcome to 'low emission zones' (LEZs) such as the West Yorkshire LEZ (WYLEZ) analysed in this paper. While the proximal motivation for CAZs may be to achieve compliance, there may well be significant cobenefits in terms of generating health and, indeed, it may be the case that these interventions are costeffective, in terms of health, in their own right.

NICE public health guidance ${ }^{10}$ describes the potential methods for the conduct of an economic analysis of public health programmes including cost-effectiveness analysis, cost-utility analysis, cost-benefit analysis and cost-consequence analysis. While this guidance demonstrates the pros and cons of each type of analysis, it is not prescriptive in which method is preferred. Where most of the benefits of an intervention are in the health sector, it is appropriate to utilise techniques from the economic evaluation of heath technologies, ${ }^{10}$ a form of cost-effectiveness analysis. We consider the use of QALYs in economic evaluation as a means to quantify any health impact and provide a basis for calculating the value for money of air quality interventions, both in theory and by example through an application of our estimates to the case study of a policy scenario of the WYLEZ compared against a 'do nothing' scenario.

\section{METHODS}

\section{Overview}

Following the approach taken by NICE for evaluating health technologies, ${ }^{10}$ only National Health Service (NHS) and Personal Social Services (PSS) costs are considered in this analysis, with costs falling outside of these budgets not taken into account, although we compare our final estimate of health-related benefits to the implementation cost of the scenario under consideration that does not fall on the health sector budget. Health benefits are quantified by using the QALY: a composite measure of number of life years and the quality weighting associated with this (health-related quality of life (HRQoL)). The QALY is anchored at 0 (assumed to represent death) and 1 (assumed to represent full health). NHS/PSS costs and QALYs are modelled over the lifetime of the affected individuals' lifetime and those falling in future years are both discounted at $3.5 \%$ per annum. ${ }^{11}$ Alternative interventions can then be compared in terms of their cost and QALY profiles and incremental cost-effectiveness ratios (ICERs) can then be used to assess cost-effectiveness by comparing this ICER with the threshold value of a QALY $^{10}$ The threshold value of a QALY represents the exchange rate between the costs and the effects that is the rate at which a healthcare decision-maker is willing to substitute health outcomes and resources. It represents the opportunity cost of the health foregone in other areas, by adopting a new technology. While a full discussion of the underlying theory behind the costeffectiveness threshold is beyond the scope of this paper, it is important to clarify that it is based on an estimate of the health opportunity cost of healthcare expenditure (because of constraints such as that imposed by a fixed budget), rather than the consumption value of health 
(for which estimates of value can be obtained through methods such as willingness to pay (WTP) or value of a statistical life (VSL)). Alternatively the threshold value of a QALY can be used in order to provide valuations in terms of net monetary (or net health) benefit. ${ }^{12}$

There is a burgeoning evidence base surrounding causal links between various health effects, in particular those affecting chronic morbidity, ${ }^{13-17}$ and poor air quality. Replicating WTP surveys to maintain up-to-date valuations of air quality impacts is expensive and time consuming (an example survey question is provided in the online supplementary appendix). Instead, quantifying the benefit associated with air pollution improvement interventions in terms of QALYs and applying an associated threshold value for a QALY gained provides a flexible and generalisable approach to estimating the impact of air quality on health and healthcare costs. QALYs are less frequently used in environmental economics in favour of WTP and VSL methods, but have great precedent in health economics for quantifying health effects. ${ }^{18-23}$ QALYs can also be used as part of cost-benefit analysis, in which case it may be desirable to value QALYs using their social consumption value. ${ }^{24}$

\section{The WYLEZ case study}

The West Yorkshire Zone, as classified by DEFRA, has the fourth most significant $\mathrm{NO}_{2}$ concentration issues in the UK (after London, West Midlands and Greater Manchester). In addition, $5.4 \%$ of all mortality in West Yorkshire in 2010 was attributable to exposure to atmospheric particles smaller than $2.5 \mu \mathrm{m}$ in aerodynamic diameter $\left(\mathrm{PM}_{2.5}\right)^{25}$ In 2011, Bradford Metropolitan District Council (BMDC) and Leeds City Council (LCC) were awarded grants by DEFRA to undertake a LEZ feasibility study. The work has focused on establishing the benefits of low emission strategies that could result from cleaner bus, freight, taxi and private care fleets.

As part of the LEZ feasibility study, Cooper and colleagues conducted a health impact assessment (HIA). It is a public document and is available online at the following URL: http://www.bradford.gov.uk/NR/ rdonlyres/1B122A0C-D989-451D-B0BE-30A46F0FF569/0/ ReportOfTheLEZFeasibilityStudy.pdf. This HIA comprises several parts: modelling of traffic and emissions under different policy scenarios, dispersion modelling, a model to convert concentrations into lower layer super output area (LSOA)-level exposure and the application of response functions that generate estimates of changes in numbers of health events given changes in exposure and baseline levels of health events. Full details can be obtained from the document itself, but some key features for the purposes of this paper are described below.

The HIA looked only at the long-term health effects from exposure to $\mathrm{PM}_{2.5}$ and $\mathrm{NO}_{2}$. The health effects of other pollutants such as ozone were therefore not considered. In addition, the acute health effects of shortterm exposure to air pollutants were not considered. These health effects are likely to be of a smaller magnitude than those considered ${ }^{26}$ and so would be unlikely to influence results. Estimates of the quantitative impact on health from exposure to poor air quality are taken from studies that were considered high quality either through being a meta-analysis identified through PubMed $^{13-17}$ or by virtue of being a study that is heavily cited and recommended by COMEAP. ${ }^{15}$ The resulting studies, details regarding study type and their estimated effects on health are shown below in table 1 .

In certain cases, more recent meta-analyses have become available and more widely used than those used in the original HIA, for instance all-cause mortality due to $\mathrm{PM}_{2.5}$ exposure in ref. 27. In addition, more health

Table 1 Exposure response functions from Cooper et $a^{\beta 0}$

\begin{tabular}{|c|c|c|c|c|c|}
\hline Health event & Pollutant & Reference & Study type & $\begin{array}{l}\text { Type of } \\
\text { effect }\end{array}$ & Exposure response function \\
\hline $\begin{array}{l}\text { All-cause } \\
\text { mortality death }\end{array}$ & $\mathrm{PM}_{2.5}$ & $\begin{array}{l}\text { Pope, } \\
\text { et } a l^{15}\end{array}$ & Cohort study (USA) & Annual & $\begin{array}{l}\text { Relative risk of } 1.06 \text { ( } 95 \% \mathrm{Cl} 1.02 \text { to } \\
\text { 1.11) per } 10 \mu \mathrm{g} / \mathrm{m}^{3} \text { increase in } \mathrm{PM}_{2.5} \\
\text { exposure }\end{array}$ \\
\hline $\begin{array}{l}\text { Coronary } \\
\text { events } \\
\text { (Bradford only) }\end{array}$ & $\mathrm{PM}_{2.5}$ & $\begin{array}{l}\text { Cesaroni, } \\
\text { et } a l^{13}\end{array}$ & $\begin{array}{l}\text { Meta-analysis of cohort } \\
\text { studies (Europe, not } \\
\text { including UK) }\end{array}$ & Annual & $\begin{array}{l}\mathrm{HR} \text { of } 1.19(95 \% \mathrm{Cl} 1.00 \text { to } 1.42) \text { per } \\
5 \mu \mathrm{g} / \mathrm{m}^{3} \text { increase in } \mathrm{PM}_{2.5} \text { exposure }\end{array}$ \\
\hline $\begin{array}{l}\text { Cases of } \\
\text { childhood } \\
\text { asthma }\end{array}$ & $\mathrm{NO}_{2}$ & $\begin{array}{l}\text { Takenoue, } \\
\text { et } a l^{17}\end{array}$ & $\begin{array}{l}\text { Meta-analysis } \\
\text { (worldwide, not including } \\
\text { UK) }\end{array}$ & Prevalence & $\begin{array}{l}\text { OR of } 1.135(95 \% \mathrm{Cl} 1.03 \text { to } 1.25) \\
\text { per } 18.8 \mu \mathrm{g} / \mathrm{m}^{3} \text { increase in } \mathrm{NO}_{2}\end{array}$ \\
\hline $\begin{array}{l}\text { Term, low } \\
\text { birthweight birth }\end{array}$ & $\begin{array}{l}\mathrm{PM}_{2.5} \text { and } \\
\mathrm{NO}_{2}\end{array}$ & $\begin{array}{l}\text { Pedersen } \\
\text { et } a l^{14}\end{array}$ & $\begin{array}{l}\text { Pooled cohort studies } \\
\text { (Europe, including UK- } \\
\text { born in Bradford) }\end{array}$ & Annual & $\begin{array}{l}\text { OR of } 1.18(95 \% \mathrm{Cl} 1.06 \text { to } 1.33) \text { per } \\
5 \mu \mathrm{g} / \mathrm{m}^{3} \text { increase in } \mathrm{PM}_{2.5} \text { exposure } \\
\text { and } 1.09(95 \% \mathrm{Cl} 1.00 \text { to } 1.19) \text { per } \\
10 \mu \mathrm{g} / \mathrm{m}^{3} \text { increase in } \mathrm{NO}_{2}\end{array}$ \\
\hline Preterm birth & $\mathrm{PM}_{2.5}$ & $\begin{array}{l}\text { Sapkota, } \\
\text { et }\left.a\right|^{16}\end{array}$ & $\begin{array}{l}\text { Meta-analysis } \\
\text { (worldwide, not including } \\
\text { UK) }\end{array}$ & Annual & $\begin{array}{l}\text { OR of } 1.15 \text { (95\% Cl } 1.14 \text { to } 1.16) \text { per } \\
10 \mu \mathrm{g} / \mathrm{m}^{3} \text { increase in } \mathrm{PM}_{2.5} \text { exposure }\end{array}$ \\
\hline
\end{tabular}


conditions have been linked with poor air quality exposure, without a meta-analysis having been performed (eg, see ref. 28, for incidence of bronchitis). In this paper, the links used in the published HIA are taken as given. The purpose of the paper is to apply the NICE framework and to demonstrate the application of a new methodology to the field of air quality using a real-world case study. The paper explores the use of cost-effectiveness analysis to inform local decision-making in WYLEZ, working with locally available data where possible. As can be seen in table 1 , only one of the health events is modelled as a response to exposure of both pollutants. Therefore, any double counting through modelling term, low birthweight births as a response to both pollutants independently is likely to have only a small impact on results obtained. However, this is a bigger consideration in the broader literature where many of the same outcomes can result from $\mathrm{PM}_{2.5}$ and $\mathrm{NO}_{2}$ and very often people are simultaneously exposed to both (see for instance discussion in ref. 29). In addition, there may be synergistic effects arising from exposure to both that are not considered in the analysis here. The study also assumed that there was no time lag between exposure to pollutants and the resulting health events; this is again another simplification that should be taken into account when looking at the results (see ref. 26 for further details on issues around modelling this lagged effect of exposure).

In this analysis, the health effects of one intervention (pre-EURO 4 buses and HGVs were upgraded to EURO 6 by 2016) were taken from an analysis undertaken as part of the LEZ feasibility studies. ${ }^{30} \mathrm{i}$ The comparison is with a 2012 baseline (no intervention).

The health effects of this scenario relative to no intervention were taken from LSOAs with centroids within the outer ring roads (ORRs) in Leeds and Bradford resulting from estimated reductions in emissions from within Leeds and Bradford ORRs of $13.502 \mathrm{t}$ of $\mathrm{PM}_{2.5}$ per annum and $352.28 \mathrm{t}$ of $\mathrm{NO}_{\mathrm{x}}$ per annum (where $50 \%$ of $\mathrm{NO}_{\mathrm{x}}$ is assumed to be $\mathrm{NO}_{2}$ for the purposes of the HIA). This is the change in emissions relative to the 2012 baseline that acts as the comparator in this evaluation, which results from the change in traffic-related emissions (background concentrations of pollutants are common to both scenarios and therefore do not affect the changes in exposure). Note that here a conservative assumption has been applied in terms of limiting the health effects to within the same area as impacted by the introduction of the LEZ. This underestimates the health impacts for two reasons. One is that a LEZ will affect traffic and so emissions and exposure in the surrounding area. The other is that emissions within the LEZ are dispersed and so may cause exposure outside of the LEZ

\footnotetext{
iAvailable for download as 'Bradford Low Emission Zone Feasibility Study' at http://www.bradford.gov.uk/bmdc/the_environment/ pollution_noise_and_nuisance/air_quality.
}

itself. Both of those would be captured in an ideal analysis, but in this paper, we apply a practical simplification that represents a lower bound on the health effects of the policy.

\section{Estimating the NHS/PSS costs and QALYs associated with air quality-related health endpoints}

Obtaining estimates of HRQoL and NHS/PSS costs for each of the events in the HIA requires some assumptions, which are detailed elsewhere. ${ }^{31}$ An example of such an assumption pertains to the conversion of attributable deaths to QALYs. According to ref. 26, exposure to $\mathrm{PM}_{2.5}$ leads to roughly 29000 attributable deaths in the UK and 340000 life years lost. We therefore assume that 11.72 life years are lost for each attributable death. In addition, we assume that each person affected loses 2 years of life (5.86 people affected per attributable death) and that they were in $75+$ age category (HRQoL for this age group is 0.73 on average according to ref. 32). After discounting, the health loss associated with an attributable death is 8.4 QALYs. A summary of the sources used is provided in table $2 .^{\text {ii }}$

For each of the health impacts estimated from the HIA, the QALYs lost and additional NHS and PSS resources used were evaluated. The central estimates of the value of these health impacts when following this approach (and valuing a QALY at $£ 20000$ ) are given in table 3. Full details of their calculation can be found in ref. 31 (see online supplementary appendix for full URL of this publication). The inclusion of QALYs and NHS/PSS costs is consistent with a pharmacoeconomic approach to cost-effectiveness analysis, such as that typically adopted by NICE for the evaluation of interventions where costs largely fall on the health sector.

\section{RESULTS}

In this section, we present the results for the valuation of this LEZ scenario using the approach discussed in the previous section. The results from these are summarised in table 4.

The HIA considers more health outcomes than mortality, with morbidity cases averted forming a substantial proportion of the value of health benefits generated from reducing exposure to traffic-related air pollution. These include neonatal complications arising from air pollution as well as NHS/PSS costs of childhood asthma cases. The single largest component of the annual effect is from the impact of reduced $\mathrm{PM}_{2.5}$ on reduced all-cause mortality where 10 equivalent deaths are averted. These are valued at $£ 1680000$ per year. This constitutes over threequarters of the total annual effect (the weight attached to

${ }^{i i}$ Data that can be made available can be obtained by contacting the corresponding author (JL) at james.lomas@york.ac.uk. These data take the form of a spreadsheet in which calculations were made. Baseline data to which response functions were applied are not able to be made publicly available due to small numbers of counts. 
Table 2 Data sources for cost and quality-adjusted life year estimates

\begin{tabular}{ll}
\hline Health event & $\begin{array}{l}\text { Sources used for } \\
\text { health cost calculation }\end{array}$ \\
\hline All-cause mortality death & 3226 \\
Coronary events (Bradford only) & $32-37$ \\
Cases of childhood asthma & $32-3537-41$ \\
Term, low birthweight birth & 33 \\
Preterm birth & 33324243 \\
\hline
\end{tabular}

Table 3 Summary of NHS/PSS costs and QALYS associated with each case of the health end points from the HIA

\begin{tabular}{|c|c|c|c|}
\hline Health outcome & $\begin{array}{l}\text { QALY } \\
\text { loss, } \\
\text { one } \\
\text { decimal } \\
\text { place } \\
\end{array}$ & $\begin{array}{l}\text { Additional } \\
\text { costs, } \\
\text { nearest } \\
£ 1000 \text { ( } \\
2013 / 2014) \\
\end{array}$ & $\begin{array}{l}\text { Combined } \\
\text { loss, } \\
\text { nearest } \\
£ 1000 \text { ( } £ \\
2013 / 2014)\end{array}$ \\
\hline All-cause death & 8.4 & - & $£ 168000$ \\
\hline Coronary event & 1.1 & $£ 28000$ & $£ 50000$ \\
\hline $\begin{array}{l}\text { Term, low } \\
\text { birthweight birth }\end{array}$ & - & $£ 2000$ & $£ 2000$ \\
\hline Preterm birth & 1.3 & $£ 24000$ & $£ 50000$ \\
\hline Childhood asthma & 0.9 & $£ 3000$ & $£ 21000$ \\
\hline
\end{tabular}

HIA, health impact assessment; NHS, National Health Service; PSS, Personal Social Services; QALY, quality-adjusted life year.

mortality vs morbidity is variable among competing methodologies, as can be seen in ref. 44, where the percentage due to mortality is higher when VSL applied to attributable deaths compared with value of life year applied to life years). The remainder of the annual effect is made up of morbidity effects of other health impacts averted through reduction in exposure to $\mathrm{PM}_{2.5}$ (and some mortality effects due to pre term birth). Within the annual effect, roughly $1 \%$ is made up of health impacts averted due to reduced exposure to $\mathrm{NO}_{2}$. However, there is a substantial one-off value of $£ 3300000$ attached to the reduction in prevalence of childhood asthma that results from reduced exposure to $\mathrm{NO}_{2}$.

\section{DISCUSSION}

This paper highlights the potential to apply a method for assessing the likely cost-effectiveness of interventions to promote air quality that has been developed for the assessment of pharmacoeconomic interventions, including those appraised by NICE. Our results indicate an estimate of the annual value of the health impact of this intervention of $£ 2080000$ per annum alongside a one-off effect on prevalence of childhood asthma worth $£ 3300000$. According to ref. 21, the net present value of the cost of implementing this scenario is $£ 6300000$. Thus, the intervention appears to be cost-effective if differences in exposure are maintained for a sufficiently long time period (roughly 1 year and 5 months assuming discount rate of $3.5 \%$ ). ${ }^{\text {ii }}$ However, a more careful consideration of alternative interventions should be used to inform a policymaker and the focus of this paper is methodological and the application is illustrative.

The use of cost-effectiveness analysis using QALY as an outcome measure is common in health technology assessment. Though there are examples of a QALY framework being applied to evaluate air quality interventions, ${ }^{45-47}$ these are relatively rare. While the advantages of the NHS/PSS costs and QALYs approach are substantial, allowing the comparison across a variety of interventions in different conditions, the approach also has its limitations and difficulties in public health evaluations. ${ }^{48}$ At present, the NHS/PSS costs and QALYs approach is used primarily where the perceived benefits are in the health sector. Ongoing work ${ }^{49}$ is exploring the potential for extending the health sector costs and QALYs approach to a multisectoral environment. However, this work remains in its infancy and approaches that allow the comparison of outcomes across several sectors (such as the damage cost method) have been preferred where substantial effects extend beyond health.

Where interventions to improve air quality are primarily aimed at improving health, should they not be compared with other health interventions, so that scarce resources can be used most efficiently? In these instances, there appears to be little justification to exclude air quality interventions from comparison with other 'health' interventions. In order to facilitate this comparison, the use of QALYs is desirable, which has been illustrated successfully in this paper.

\section{Strengths}

Applying cost and QALY methods from economic evaluation $^{\text {iv }}$ in healthcare allows the assessment of costeffectiveness from a healthcare perspective and facilitates comparison with other health interventions. There is currently a robust health economic evidence base supporting some key public health interventions (eg, smoking cessation, alcohol screening and brief interventions, prescribing exercise classes). ${ }^{v}$ Recent research by COMEAP and others has demonstrated how poor air quality should join the list of public health priorities. Looking at

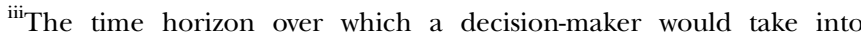
account costs and benefits is clearly an important issue in this scenario, but this is true more broadly in terms of air quality, public health or even medical evaluations. In principle, the appropriate time horizon would be the period over which costs and benefits are different for comparators under consideration. In practice, however, one might adopt a time horizon in keeping with the specific policy under consideration, for example, the expected longevity of new buses.

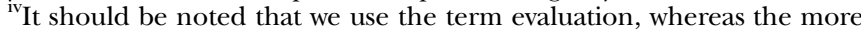
precise wording might be ex ante evaluation, since we are constructing a model to evaluate the effects of an intervention before it has been implemented. Ex post evaluation refers to an analysis of an intervention after it has taken place, typically by examining changes in outcomes following its implementation.

${ }^{\mathrm{v}}$ See NICE website: https://www.nice.org.uk/guidance/published? type $=$ ph.
} 
Table 4 Summary of results

\begin{tabular}{|c|c|c|c|}
\hline Health event & Pollutant & $\begin{array}{l}\text { Number averted per year by implementing } \\
\text { pre EURO } 4 \text { buses and HGVs were } \\
\text { upgraded to EURO } 6 \text { by } 2016\end{array}$ & $\begin{array}{l}\text { Total value per year, } \\
\text { nearest } £ 10000(£ 2013 / 2014)\end{array}$ \\
\hline All-cause mortality death & $\mathrm{PM}_{2.5}$ & 10 & $£ 1680000$ \\
\hline Coronary events (Bradford only) & $\mathrm{PM}_{2.5}$ & 5 & $£ 250000$ \\
\hline Term, low birthweight birth & $\mathrm{PM}_{2.5}$ & 7 & $£ 20000$ \\
\hline Term, low birthweight birth & $\mathrm{NO}_{2}$ & 10 & $£ 20000$ \\
\hline Preterm birth & $\mathrm{PM}_{2.5}$ & 2.2 & $£ 110000$ \\
\hline Total annual effect & & & $£ 2080000$ \\
\hline Cases of childhood asthma & $\mathrm{NO}_{2}$ & 157 & $£ 3300000^{*}$ \\
\hline
\end{tabular}

${ }^{*}$ Not annual effect but rather a one-off reduction in cases due to reduced prevalence.

$\mathrm{NO}_{2}$, nitrogen dioxide; $\mathrm{PM}_{2.5}$, atmospheric particles smaller than $2.5 \mu \mathrm{m}$ in aerodynamic diameter.

England only, there were 80000 deaths due to smoking among adults over 35 in $2013^{50}$ and 6500 deaths related to alcohol in 2012. ${ }^{51}$ This compares with 40000 attributable deaths per year in the UK. ${ }^{1}$ The methods outlined above will allow local authorities to prioritise low emission strategies (supported by health and economic benefits) alongside other public health interventions.

\section{Limitations}

It is worth noting that it may not always be possible to estimate an effect of a health event on QALYs or NHS/ PSS costs due to data limitations or potentially a lack of sensitivity in the instrument for measuring health. One such example was our inability to estimate a QALY loss associated with term, low birthweight birth. In such cases, it is worth considering the total health effects that can be assigned a QALY loss as potentially a lower bound, since others may exist but cannot be valued for one of the reasons above. It is also worth noting that if the issue is that the health effect is too small to be detected, then it is unlikely to have a large bearing on decision-making.

The results presented above only consider a point estimate for the effects of the LEZ scenario, this masks the large uncertainty associated with each of the estimated components. One such uncertainty arises from the length of lag between exposure and health effect. Indeed this is one aspect of uncertainty, but there are many more that are relevant to the decision-maker. Presenting only the point estimates is useful for a comparison of the expected values generated by the LEZ scenario. A fuller consideration of uncertainty would take in to account the following stochastic elements:

1. Estimated reduction in emissions;

2. Modelled dispersion;

3. Health effects of exposure to air pollutants;

4. Values of health impacts;

5. Assumptions made in generating estimates of QALY.

The analysis makes only one comparison between the introduction of pre-EURO 4 buses and HGVs are upgraded to EURO 6 by 2016 and a preintervention (2012) baseline. However, decision-makers are likely to be faced with a multitude of competing alternatives, both air quality interventions and other public health interventions. Thus, a more useful analysis would include an assessment of the cost-effectiveness of several relevant comparators rather than comparing one intervention with a preintervention baseline. Importantly, the principle of using a common measure of benefit (such as QALYs) is crucial for aiding comparison. There are projections of how the transport fleet may evolve that is often referred to as a 'do nothing' scenario, which is the preferred comparator in ref. 21. However, it is potentially preferable to use the preintervention baseline if the assumptions underlying the projection are questionable. For example, enforcing the 'do nothing' projections may not be without cost if neighbouring regions implemented a LEZ and the associated consequences in terms of relocation of older vehicles within the national transport fleet. The purpose of the case study is to illustrate the cost-effectiveness methodology using QALYs as a measure of health benefits, based on NICE guidance. We only claim that the illustration is generalisable to the extent that the health effects considered would be common to similar types of interventions under consideration. These would include CAZs across UK and therefore this paper will be useful to local decision-makers across the country. However, there are many specific features of the case study and the interested reader may wish to investigate other similar studies if they are interested in the evaluation of air pollution policy more generally (see for instance refs. 22, 23 and 52).

In the context of a transport intervention, further costs may be of interest, for instance those that fall on bus companies, or on council-provided services or sectors such as the educational sector. The illustration in this paper provides valuable information on the health sector consequences, but further research on the impacts on other sectors would be complementary and valuable.

\section{CONCLUSION}

Interventions to improve air quality and health should be evaluated and where improvement of population health is the primary objective, cost-effectiveness analysis using 
the NICE reference case with NHS/PSS costs and QALYs framework is an appropriate methodology. Alternative methodologies exist such as cost-benefit analysis, which has greater precedence in the environment literature. It should be noted that NHS/PSS costs and QALYs can be used as an input into cost-benefit analysis also.

\author{
Author affiliations \\ ${ }^{1}$ University of York, Centre for Health Economics, York, UK \\ ${ }^{2}$ Academic Unit of Health Economics, University of Leeds, Leeds, UK \\ ${ }^{3}$ City of Bradford Metropolitan District Council, Bradford, UK \\ ${ }^{4}$ Improvement Academy, Yorkshire and Humber Academic Health Science \\ Network, UK \\ ${ }^{5}$ City of York Council, York, UK \\ ${ }^{6}$ Ecometrics Research and Consulting, Reading, UK \\ ${ }^{7}$ Wakefield Council, Wakefield, UK \\ ${ }^{8}$ Leeds City Council, Leeds, UK \\ ${ }^{9}$ CREAL (Centre de Recerca en Epidmiologia Ambiental)
}

Acknowledgements This article presents independent research by the National Institute for Health Research Collaboration for Leadership in Applied Health Research and Care Yorkshire and Humber (NIHR CLAHRC YH). www. clahrc-yh.nir.ac.uk. The views and opinions expressed are those of the authors, and not necessarily those of the NHS, the NIHR or the Department of Health. In addition, helpful comments were provided at earlier presentations of this work at Public Health England's Annual UK Review Meeting on Outdoor and Indoor Air Pollution Research and the Air Quality Improvement Collaborative Event. The authors are extremely grateful to the reviewers who provided a comprehensive and constructive evaluation of the paper, from which the paper has greatly benefited. They also acknowledge funding from DEFRA, during the time period over which the study was conducted. The authors acknowledge funding from a broad range of organisations. Governmental organisations include UK government (Environment Agency, Defra, Department for Health), the European Commission, WHO and OECD. NGOs include the Health Environment Alliance, European Environment Bureau and Greenpeace. MH's work is funded by some industrial organisations, but none relevant to local air quality.

Contributors $\mathrm{JL}$ was responsible for the initial draft before comments from all authors and led the conduct of the analysis that formed the basis of the paper. LS contributed to the drafting of the paper in addition to having provided input into the analysis undertaken. SJ, MM and EB commented on several versions of the draft and analysis as well as having helped to set the overall direction for the paper. MH, MA, DRR and HW provided substantial comments on the draft and analysis, and provided expertise on related work. DC provided substantial comments on the draft and analysis and was responsible for the initial health impact analysis on which this work is based. RC provided substantial input and comments on the analysis and was contributed greatly to the initial health impact analysis on which this work is based. GR and LB were heavily involved in the drafting and conduct of analysis as well as having helped to set the overall direction for the paper.

\section{Funding National Institute for Health Research (NIHRCLAHRCYH).}

Disclaimer The views and opinions expressed are those of the authors, and not necessarily those of the NHS, the NIHR or the Department of Health.

Competing interests $\mathrm{RC}$ reports a grant from DEFRA, during the conduct of the study. $\mathrm{MH}$ is funded by a broad range of organisations. Governmental organisations include UK government (Environment Agency, Defra, Department for Health), the European Commission, WHO and OECD. NGOs include the Health Environment Alliance, European Environment Bureau and Greenpeace. MH's work is also funded by some industrial organisations, but none relevant to local air quality.

Provenance and peer review Not commissioned; externally peer reviewed.

Data sharing statement No additional data are available.
Open Access This is an Open Access article distributed in accordance with the terms of the Creative Commons Attribution (CC BY 4.0) license, which permits others to distribute, remix, adapt and build upon this work, for commercial use, provided the original work is properly cited. See: http:// creativecommons.org/licenses/by/4.0/

\section{REFERENCES}

1. Royal College of Physicians. Every breath we take: the lifelong impact of air pollution. London: RCP, 2016.

2. Brauer M. Air pollution, stroke, and anxiety. BMJ 2015;350:h1510.

3. Power MC, Kioumourtzoglou M-A, Hart JE, et al. The relation between past exposure to fine particulate air pollution and prevalent anxiety: observational cohort study. BMJ 2015;350:h1111.

4. Shah ASV, Lee KK, McAllister DA, et al. Short term exposure to air pollution and stroke: systematic review and meta-analysis. BMJ 2015;350:h1295.

5. Hawkes N. Air pollution in UK: the public health problem that won't go away. BMJ 2015;350:h2757.

6. NICE. Beta interferon and glatiramer acetate for the treatment of multiple sclerosis. 2002. https://www.nice.org.uk/guidance/ta32 (accessed 1 Jun 2016).

7. NICE. Smoking: workplace interventions. 2007. https://www.nice.org uk/guidance/ph5 (accessed 1 Jun 2016).

8. Lim SS, Vos T, Flaxman AD, et al. A comparative risk assessment of burden of disease and injury attributable to 67 risk factors and risk factor clusters in 21 regions, 1990-2010: a systematic analysis for the Global Burden of Disease Study 2010. Lancet 2012;380:2224-60.

9. Martenies SE, Wilkins D, Batterman SA. Health impact metrics for air pollution management strategies. Environ Int 2015;85:84-95.

10. NICE. Methods for the development of NICE public health guidance. 3rd edn. 2012

11. Treasury HM. The Green Book: appraisal and evaluation in central government. 2013. https://www.gov.uk/government/publications/thegreen-book-appraisal-and-evaluation-in-central-governent (accessed 1 Jun 2016)

12. Claxton K. The irrelevance of inference: a decision-making approach to the stochastic evaluation of health care technologies. J Health Econ 1999;18:341-64.

13. Cesaroni G, Forastiere F, Stafoggia M, et al. Long term exposure to ambient air pollution and incidence of acute coronary events: prospective cohort study and meta-analysis in 11 European cohorts from the ESCAPE Project. BMJ 2014;348:f7412.

14. Pedersen M, Giorgis-Allemand L, Bernard C, et al. Ambient air pollution and low birthweight: a European cohort study (ESCAPE). Lancet Respir Med 2013;1:695-704.

15. Pope CA, Burnett RT, Thun MJ. Lung cancer, cardiopulmonary mortality, and long-term exposure to fine particulate air pollution. JAMA 2002;287:1132-41.

16. Sapkota A, Chelikowsky AP, Nachman KE, et al. Exposure to particulate matter and adverse birth outcomes: a comprehensive review and meta-analysis. Air Qual Atmos Health 2012;5:369-81.

17. Takenoue $\mathrm{Y}$, Kaneko T, Miyamae T, et al. Influence of outdoor NO2 exposure on asthma in childhood: meta-analysis. Pediatr Int 2012;54:762-9.

18. Arigoni Ortiz R, Markandya A, Hunt A. Willingness to pay for mortality risk reduction associated with air pollution in São Paulo. Rev Bras Econ 2009;63:3-22.

19. Chilton S, Covey J, Jones-Lee M, et al. Health benefits associated with reductions in air pollution. 2004

20. Tekeşin C, Ara S. Measuring the value of mortality risk reductions in Turkey. Int J Environ Res Public Health 2014;11:6890-922.

21. Ricardo AEA. Economic assessment of Bradford and Leeds Low Emission Strategies: cost benefit analysis. 2014. https://www. bradford.gov.uk/NR/rdonlyres/1B122A0C-D989-451D-B0BE30A46FOFF569/0/ReportOfTheLEZFeasibilityStudy.pdf (accessed 1 Jun 2016)

22. Vedrenne $\mathrm{M}$, Borge R, Lumbreras J, et al. An integrated assessment of two decades of air pollution policy making in Spain: impacts, costs and improvements. Sci Total Environ 2015;527-528: 351-61.

23. Wang $X$, Mauzerall DL. Evaluating impacts of air pollution in China on public health: Implications for future air pollution and energy policies. Atmos Environ 2006;40:1706-21.

24. Donaldson $\mathrm{C}$, Baker $\mathrm{R}$, Mason $\mathrm{H}$, et al. The social value of a QALY: raising the bar or barring the raise? BMC Health Serv Res 2011;11:8.

25. Gowers AM, Miller BG, Stedman JR. Estimating Local Mortality Burdens associated with Particulate Air Pollution. Public Health 
England. 2014. https://www.gov.uk/government/uploads/system/ uploads/attachment_data/file/332854/PHE_CRCE_010.pdf (accessed 1 Jun 2016).

26. COMEAP. Mortality effects of long-term exposure to particulate air pollution in the UK. 2010.

27. Hoek G, Krishnan RM, Beelen R, et al. Long-term air pollution exposure and cardio- respiratory mortality: a review. Environ Health 2013;12:43.

28. Zemp E, Elsasser S, Schindler C, et al. Long-term ambient air pollution and respiratory symptoms in adults (SAPALDIA study) The SAPALDIA team. Am J Respir Crit Care Med 1999;159:1257-66.

29. COMEAP. Nitrogen dioxide: health effects of exposure. 2015. https:// www.gov.uk/government/publications/nitrogen-dioxide-health-effectsof-exposure (accessed 1 Jun 2016).

30. Cooper D, Crowther R, Dixon R, et al. West Yorkshire Low Emission Zone feasibility study: health impact assessment methodology and preliminary findings (Leeds and Bradford). 2014. https://www. bradford.gov.uk/NR/rdonlyres/1B122A0C-D989-451D-B0BE30A46F0FF569/0/ReportOfTheLEZFeasibilityStudy.pdf (accessed 1 Jun 2016).

31. Lomas J, Schmitt L, Jones S, et al. Health costs savings of West Yorkshire Low Emission Zone. 2015. http://www.improvementacademy. org/documents/Projects/air_quality/Costs\%20and\%20benefits\% 20 associated\%20with\%20emissions.pdf (accessed 1 Jun 2016).

32. Kind $\mathrm{P}$, Hardman $\mathrm{G}$, Macran S. "UK population norms for EQ-5D," Centre for Health Economics, University of York. Working Paper 172chedp, November. 1999

33. Curtis L. Unit Costs of Health and Social Care 2014. 2014. http:// www.pssru.ac.uk/project-pages/unit-costs/2014/ (accessed 1 Jun 2016).

34. ONS. '2011 Census', Office for National Statistics. 2012. https:// www.ons.gov.uk/census/2011census (accessed 1 Jun 2016)

35. ONS. National Life Tables, 2011-2013. 2014. http://www.ons.gov. uk/peoplepopulationandcommunity/birthsdeathsandmarriages/ lifeexpectancies/bulletins/nationallifetablesunitedkingdom/2014-0925 (accessed 1 Jun 2016).

36. Robinson M, Palmer S, Sculpher M, et al. Cost-effectiveness of alternative strategies for the initial medical management of non-ST elevation acute coronary syndrome: systematic review and decision-analytical modelling. Health Technol Assess 2005;9:iii-iv, ix-xi, 1-158.

37. Sullivan PW, Slejko JF, Sculpher MJ, et al. Catalogue of EQ-5D scores for the United Kingdom. Med Decis Mak 2011;31:800-4.
38. Bajekal M, Primatesta P, Prior G, eds. Health Survey for England 2001: Respiratory symptoms, atopic conditions and lung function. London: The Stationery Office, 2003.

39. Gupta R, Sheikh A, Strachan DP, et al. Burden of allergic disease in the UK: secondary analyses of national databases. Clin Exp Allergy 2004;34:520-6.

40. Oswald H, Phelan PD, Lanigan A, et al. Outcome of childhood asthma in mid-adult life. BMJ 1994;309:95-6.

41. Peters J, Stevenson M, Beverley C, et al. The clinical effectiveness and cost-effectiveness of inhaler devices used in the routine management of chronic asthma in older children: a systematic review and economic evaluation. Health Technol Assess 2002;6:1-167.

42. Colbourn T, Asseburg C, Bojke L, et al. Prenatal screening and treatment strategies to prevent group B streptococcal and other bacterial infections in early infancy: cost-effectiveness and expected value of information analyses. Health Technol Assess 2007;11:1-226, iii.

43. Mangham LJ, Petrou S, Doyle LW, et al. The cost of preterm birth throughout childhood in England and Wales. Pediatrics 2009;123: e312-327.

44. Schucht S, Colette A, Rao S, et al. Moving towards ambitious climate policies: monetised health benefits from improved air quality could offset mitigation costs in Europe. Environ Sci Policy 2015;50:252-69.

45. Cohen JT, Hammitt JK, Levy Jl. Fuels for urban transit buses: a cost-effectiveness analysis. Environ Sci Technol 2003;37:1477-84.

46. Coyle D, Stieb D, Burnett R, et al. Impact of particulate air pollution on quality-adjusted life expectancy in Canada. J Toxicol Environ Health Part A 2003;66:1847-64.

47. Hubbell BJ. Implementing QALYs in the analysis of air pollution regulations. Environ Resour Econ 2006;34:365-84.

48. Weatherly $\mathrm{H}$, Drummond $\mathrm{M}$, Claxton $\mathrm{K}$, et al. Methods for assessing the cost-effectiveness of public health interventions: key challenges and recommendations. Health Policy 2009;93:85-92.

49. Claxton K, Walker S, Palmer S, et al. "Appropriate Perspectives for Health Care Decisions," Centre for Health Economics, University of York. Working Paper CHE RP, 2010:54

50. HSCIC. Statistics on Smoking, England-2014. 2014. http://www. hscic.gov.uk/catalogue/PUB14988 (accessed 1 Jun 2016).

51. HSCIC. Statistics on Alcohol-England, 2014. 2014. http://www hscic.gov.uk/catalogue/PUB14184 (accessed 1 Jun 2016).

52. Holman C, Harrison R, Querol X. Review of the efficacy of low emission zones to improve urban air quality in European cities. Atmos Environ 2015;111:161-9. 